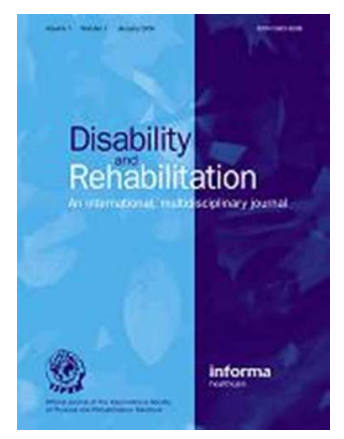

\title{
Burden of treatment in the light of the International Classification of Functioning, Disability and Health: A "Best Fit" Framework Synthesis
}

\begin{tabular}{|r|l|}
\hline Journal: & Disability and Rehabilitation \\
\hline Manuscript ID & TIDS-06-2015-113.R1 \\
\hline Manuscript Type: & Review \\
\hline Keywords: & $\begin{array}{l}\text { Review, burden of treatment, ICF, comprehensive ICF core sets, long term } \\
\text { conditions }\end{array}$ \\
\hline
\end{tabular}


1 Review

2 Burden of treatment in the light of the International Classification of Functioning,

3 Disability and Health: A "Best Fit" Framework Synthesis

4

5 Abstract

6 Purpose: This systematic literature review aimed to 1) summarise and explain the concept

7 of Burden of Treatment (BoT) using the International Classification of Functioning, Disability

8 and Health (ICF) terminology, and 2) inform the development of a future Comprehensive ICF

9 Core Set for BoT.

10 Method: Searches on EMbase, Medline, CINAHL and Psychinfo were conducted. Only 11 qualitative studies were considered for inclusion. The screening and data extraction stages

12 were followed by a "Best-fit" framework synthesis and content analysis, using the 13 established ICF linking rules. Screening, data extraction, quality appraisal and data analysis 14 were performed by two independent researchers.

15 Results: Seventeen studies were included in this review. The "Best-fit" framework synthesis 16 generated 179 subthemes which identified that BoT impacts negatively on Body Functions 17 and Structures, restricts valued Activities and Participation and influences Contextual 18 Factors through life roles, self-identify and relationships. The identified subthemes were 19 linked to 77 ICF categories.

20 Conclusions: This study is part of the preparatory phase of a Comprehensive ICF Core Set for 21 BOT and our findings will inform the further needed studies on this phase. The use of ICF 22 terminology to describe BoT provides an accessible route for understanding this complex 23 concept, which is pivotal for rethinking clinical practice. 
26 Review, burden of treatment, ICF, comprehensive ICF core sets, long term conditions

\section{Introduction}

Patients' decisions regarding treatment options, such as which treatment to receive and how much they adhere to treatment recommendations, are related to the anticipated and actual experience of undertaking the treatment [1], particularly, the perceived burden of treatment (BoT)[2]. BoT has been described as the increased demand experienced from performing self-care activities, undertaking treatment regimens and monitoring health outcomes [3]. It also includes the impact of treatment on patient functioning and well-being [4]. Increased BoT is associated with non-adherence, wasted resources, poor health

37 outcomes, reduced quality of life and, ultimately, with increased mortality [3-7]. Health professionals therefore need to be sensitive to recognising, understanding and reducing BoT, in order to balance the potential benefits and burdens of treatments and maximise adherence $[7,8]$.

42 The International Classification of Functioning, Disability and Health (ICF), developed by the World Health Organization, provides a framework for the description of health and healthrelated states within a common terminology $[9,10]$. This classification, with its four components (Body Functions and Structures, Activities and Participation, Environmental Factors and Personal Factors) reflects the biopsychossocial model in a unified and coherent

47 view of various dimensions of health (biological, individual and social) [10]. The ICF proposes that patients are not a "passive receiver of medical care" [11]. Rather, their experiences of 
49 illness are more than just the direct impact of disease on Body Functions and Structures (i.e.,

50 physiological systems or anatomical structures): they are influenced by the effect of health

51 conditions on their ability to undertake valued activities (such as walking and dressing) and

52 to participate in life situations (such as work, leisure and family). Each patient's illness

53 experience is also influenced by both Environmental Factors (i.e., physical, social and

54 attitudinal environment in which patient live, such as family support or wheelchair provision)

55 and Personal Factors (i.e., attributes of the patient with an internal influence on functioning

56 and disability, such as resilience or skills). The ICF captures these various perspectives of

57 functioning, disability and health, and has been increasingly applied by healthcare

58 professionals worldwide, as the reference framework for describing health according to the

59 biopsychosocial model [11].

60

61 The concept of BoT has not been previously aligned with the ICF framework; however, the

62 conceptual connections are apparent. Patients' experiences and perceptions of BoT have

63 been shown to relate to various factors such as fatigue or pain (Body Functions) [6, 12],

64 family circumstances, treatment design, health care systems (Environmental Factors) [4-8,

65 12-16] and Personal Factors [4-8, 12-16]. Many health professionals are familiar with and

66 applying the ICF in research and clinical practice [11]. The ICF framework can therefore act

67 as a useful tool for elucidating the complex concept of BoT. As a novel concept, BoT is

68 receiving increasing attention in the literature $[17,18]$ however, robust outcome measures,

69 to cover the complexity of this concept across conditions are still being developed and

70 fundamental understanding of this concept, based on the perspectives of patients and

71 researchers, has been generated by qualitative studies $[4,18]$. Linking the findings from

72 these studies with the ICF will inform future developments of an ICF Core Set for BoT. 
74 The development of ICF Core Sets is recommended by the World Health Organisation as 75 they represent a list of categories specifically relevant for a health condition or context, 76 promoting the applicability of the ICF in clinical practice $[19,20]$. ICF Core Sets are designed 77 in comprehensive and/or short versions. The former are exhaustive lists of categories used 78 to describe a health condition or context; the latter represent only the most essential of 79 these categories [20]. Recent guidance on the development of ICF Core Sets has been 80 published and recommends a three stage process: a preparatory phase, followed by an 81 international ICF consensus conference and a last phase, which consists of the 82 implementation of the first version of the ICF Core Set [20]. The preparatory phase includes 83 a systematic literature review which aims to gather the perspectives of researchers and 84 identify aspects of functioning that can then be linked to the ICF through the established 85 linking rules $[9,20]$. The type and characteristics of the systematic review may vary in this preparatory phase [20]. In this particular case, it is important to consider that the concept of

87 BoT is complex and recent in the literature $[3,18,21]$, and has not yet been widely linked to measurement tools [22].

90 This systematic qualitative literature review aimed to i) summarise and explain the concept 91 of BoT using the ICF terminology, and ii) inform the development of a future Comprehensive 92 ICF Core Set for BoT. The results of this study will facilitate communication within 93 multidisciplinary teams regarding BoT; allow the concept of BoT to be mapped to the ICF 94 and therefore understood and recognised among more health professionals; and ultimately, 95 inform the development of instruments/assessment tools of BoT. 
Methods

99 This qualitative literature review was guided by the Preferred Reporting Items for 100 Systematic Reviews and Meta-Analyses (PRISMA) statement, developed to promote optimal 101 clarity, transparency and reliability of systematic literature reviews [23]. The following 102 sections adopted the PRISMA terminology, with the necessary adaptations for a qualitative 103 literature.

Eligibility criteria

106 Qualitative studies that focused on patients' experiences of BoT in any health condition 107 were sought. The decision to only include qualitative studies was based on the need to gain 108 a rich and deep understanding of "what" BoT is, from the perspective of both patients and 109 researchers, and to then link this to "how" it is represented in the ICF. Therefore, studies 110 met the inclusion criteria if they: 1) used both qualitative data collection and analysis 111 methods; 2) contained the expressions "treatment burden" or "burden of treatment" in the 112 title or abstract and 3) considered BoT as the main focus or included BoT in the research 113 questions. Studies that may have contained the expressions "treatment burden" or "burden 114 of treatment" only in the body of the paper, but not in the title or abstract, were excluded.

115 This was used as an indicator of studies that have BoT as their main focus, and would 116 therefore explore this topic in greater depth. Studies describing "burden of disease", 117 "caregiver burden", "financial burdens to society or health services"; not written in English 118 or Portuguese; and, those not including qualitative data were also excluded. 
121 The search was undertaken electronically in four different databases - EMbase, Medline,

122 CINAHL and Psychinfo - aiming to achieve an extensive search strategy that would cover the 123 available studies focusing on BoT. The key words "treatment burden" OR "burden of 124 treatment" were used in all the listed databases. No restrictions were established regarding 125 treatment intervention, health condition, participant demographics, year of publication or 126 study settings. No filters were used in any of the databases. The search was initially 127 conducted in June 2012 and updated in December 2014.

Screening and study selection

130 Two blinded researchers screened the titles, abstracts and, when necessary, full texts of all 131 studies to determine inclusion and exclusion and remove duplicates. In order to avoid early 132 incorrect filtering of qualitative studies, no restrictions regarding paradigm were set on the 133 data bases and the identification of qualitative studies was undertaken manually, during the screening of titles and abstracts [24].

Quality appraisal

137 The Critical Appraisal Skills Programme Checklist for qualitative studies [25] was used to 138 assess the quality of studies. Quality appraisal was initially performed independently, and 139 then discussed and agreed, by two researchers [SH and $\mathrm{KH}$ ]. An increasing body of evidence 140 proposes that neither study design nor quality assessment scores should be used to exclude 141 qualitative studies [26, 27]. All studies were therefore included and analysed regardless of 142 their design or quality score. Quality scores are provided to enrich the description of the 143 included studies. 
145 Synthesis of results

146 The extracted data were analysed using two methods: firstly a qualitative "Best-fit" 147 framework synthesis; secondly a content analysis applying the ICF linking rules [9]. Both 148 methods are described below. "Data" were defined as both direct primary quotations 149 presented in the included studies and authors' analytical interpretations presented in either 150 the results/findings or discussion sections. The use of both "quotations" and "analytical 151 interpretations" as data for this literature review aimed to allow the gathering of a richer set 152 of data to better illustrate the concept of BoT. This approach has been used in previous 153 reviews of qualitative studies [28].

154

"Best-fit" framework synthesis. "Best-fit" framework synthesis uses the conceptual categories of an existing model or theory to facilitate thematic data extraction and analysis.

157 This synthesis method offers the means to test, reinforce and build on an existing published 158 model, conceived for a potentially different but relevant population or context [26, 27, 29].

159 The ICF was selected as the model of "Best-fit" to explore how BoT may be conceptualised 160 within a biopsychosocial perspective of health [10]. An a priori framework using the ICF 161 components (Body Functions and Structures, Activities and Participation, Environmental 162 Factors and Personal Factors) was used to extract data from the included studies. NVivo software (v.10 QSR International Pty Ltd., Melbourne, AU) was used to aid data management.

Framework analysis allows a description of both a priori and newly emerged themes. 167 Following extraction, data attributed to the a priori framework were further thematically 168 analysed, grouping similar issues to generate a list of emergent themes and subthemes. For 
169 instance, the quotes "One individual adopted a more generally sedentary lifestyle to prevent symptoms rather than undertake physical activity alongside their peers" [16] and "Fatigue

171 alongside breathlessness and cough, was reported as a factor limiting ability to keep up with 172 peers, and also as a cause of low motivation" [16] were both coded under the theme 173 "Participation linked to Body Functions and Structures" and the subtheme "Symptoms 174 limiting participation with peers".

The themes and subthemes and the links and conflicts between them were thereafter used 177 to explain the concept of BoT from the perspective of the ICF.

Content analysis following the ICF linking rules. Content analysis, applying the ICF linking rules [9], was undertaken to classify the subthemes generated as previously described, against the most appropriate ICF category. According to these rules, meaningful concepts should be extracted from a text prior to assigning the ICF categories [30]. The example below, extracted from the analysis, illustrates this process:

The subtheme (generated by "Best-fit" synthesis) "Having a routine as a strategy to reduce treatment workload and promote adherence" was analysed and the following meaningful concepts were identified: i) "having a routine as a strategy to reduce treatment workload"; ii) "having a routine as a strategy to promote adherence" and iii) "reduced workload promotes adherence".

191 Two researchers experienced in using the ICF and with a deep understanding of the concept of BoT [ACG and CJ] independently linked the meaningful concepts to the appropriate ICF 
193 categories. The example above was coded as d230 (Carrying out a daily routine); the 194 concepts "treatment workload" and "adherence" were coded as not covered by the ICF and 195 the concept "having coping strategies" was coded as Personal Factors. The agreement 196 between the codifications of both researchers was calculated with Cohen's Kappa statistics 197 [31], using IBM SPSS statistics (Version 21, IBM Corp. Released 2012, Armonk, NY). The 198 strength of agreement associated to the Cohen's Kappa statistics can be classified as poor $199(<0)$, slight $(0.00-0.20)$, fair $(0.21-0.40)$, moderate $(0.41-0.60)$, substantial $(0.61-0.80)$ or 200 almost perfect (0.81-1.00) [32]. Any disparities were discussed by the same researchers, a 201 third party [SHD] resolved disagreements and a final list was generated.

\section{Results}

205 Study selection

206 The search generated 1736 studies. Once duplicates $(n=590)$ were removed, 1146 abstracts 207 and titles were screened; 378 full texts were considered for eligibility. Studies not using 208 qualitative methods ( $n=167)$, or not exploring patients' perspective of BoT $(n=194)$ were 209 excluded. Seventeen studies met the inclusion criteria and were included in this review. A 210 PRISMA flow chart illustrating the study selection process is presented in figure 1. 
216 The samples of the included studies show a wide range of ages (from 7 to 96 years old),

217 health conditions and countries. Further details about the included studies can be found in 218 table 1. 
222 The quality scores for regarding aspects such as recruitment, data collection, validity, 223 methodology, relationship between researchers and participants, ethical issues, data 224 analysis and relevance of the findings were considered high in all included studies. However, 225 the "relationship between researchers and participants" and a detailed discussion of 226 "ethical issues" were often less clear.

227

228 ICF components applied to the concept of burden of treatment: best-fit framework synthesis 229

Burden of Treatment and Body Functions and Structures. All studies reported BoT 231 experienced as either physical and/or emotional side effects. Applying the ICF, these side232 effects can be considered as treatment induced impairments to Body Functions and 233 Structures additional to those generated by the disease itself. These included pain, fatigue 234 and nausea and altered emotional functions, such as feeling anxious or depressed. For 235 instance, patients using Percutaneous Endoscopic Gastrostomies described a large range of treatment generated physical impairments:

"Blockage, leakage, site infection, tube falling out, emesis caused by excessively rapid infusion of feed, sleep difficulties due to noise from machines, bleeding from PEG [Percutaneous Endoscopic Gastrostomies] sites when coughing, and malodorous leakage from the stoma. Feeling seek and terrible coughing that leads to vomiting, nausea, regurgitation or heartburn (...) [and] abdominal pain" [8]. 
244 The included studies also described the increased treatment workload (BoT), which was 245 frequently required in order to manage the side-effects (Impairments in Body Functions and 246 Structures) generated by the treatments.

247

248 "The primary issue during the first injections was adjusting to the cycle of symptoms and 'side effects'" [12].

251 Finally, impairments in Body Functions and Structures often reduced patients' physical 252 capacity to engage with the recommended treatment requirements. For instance a patient 253 with diabetes, stated:

"I was supposed to look at my feet once a week but I can't see my feet because of my poor vision" [4].

257

258 Treatment induced impairments were also frequently reported as contributing to 259 restrictions in patients' activities and their ability to participate in life roles, and it was the 260 impact of treatments on participation restriction that appeared to be most burdensome for 261 patients. concentrate" [4]. 
267 How BoT relates to Activities and Participation is described under the following section.

268

269 Burden of Treatment and Activities and Participations. The studies also identified that

270 treatment regimens often required patients to engage in a complex set of new and

271 additional treatment activities; for instance, exercising, learning about treatment options

272 and modifying diets. These activities took time and impacted on patients' ability to engage

273 in their valued activities. According to the included studies, participation in valued

274 occupational, social and leisure activities, sports or other hobbies contributed to patients'

275 identity and sense of self. Maintaining these activities was therefore seen as a priority and a

276 way of keeping a "normal life". For instance, one woman worried about the impact of

277 injections for spasmodic dysphonia on her valued activity of hiking:

278

279

280

I'm more concerned that [if I have the treatment] I'm not going to be able to go hiking with my friends" [12].

281

282

Many patients therefore engaged in complex decision making and prioritisation, adapting

their life to enable both their treatment and meaningful activities to occur.

284

285

286

287

288

However, the ability to maintain a stable self-identity by participation in valued activities

289

and roles was often seen as a greater priority than engaging in treatment. Participants of

290

the included studies described the process of making rational decisions to modify or even

URL: http:/mc.manuscriptcentral.com/dandr Email: davemuller@suffolk.ac.uk 
291 cease their adherence to treatments, in order to preserve aspects of participation, such as career or social/leisure activities:

293

"When I am out with friends, I don't carry them (enzymes) like my parents tell me to" [13].

296

Conversely, when treatment activities were meaningful, compatible with patients' valued

activities or caused less disruption to participation were seen as less burdensome:

299

"I used to not be able to do anything when I went to parties and now [thanks to oral immunotherapy] I can sit with other kids and actually enjoy ice cream instead of watching ... I was sort of glad I could be more like normal kids" [36].

A further link was identified between the concept of BoT, Activities and Participation and Environmental Factors. For instance the financial costs of treatment (which would be classified as Environmental Factors) were described as a factor contributing to a restriction in family leisure activities (Activities and Participation).

311

312 In other cases, where treatment-induced activity restrictions might otherwise have led to 313 non-adherence, involvement and support of relatives (also considered Environmental 314 Factors) increased patients' capacity to engage in treatment and promoted adherence. 

"I'm getting a repeat [prescription], my daughter (takes) it up to the chemist and X in the chemist (takes) it to the doctor, (gets) everything signed and it will be ready today,

Burden of Treatment and Environmental Factors. Environmental Factors were reported as sources of BoT by all studies in this review. Aspects such as health policies and health professionals' attitudes were described as causes of BoT through their disruption to patients' self-identity, as demonstrated by this quote, about a patient with tuberculosis:

Further information as to how BoT relates to the Environmental Factors is described in the following section. staff with her concerns, for fear of recrimination" [15].

Family support, attitudes of health professionals, architectural barriers or treatment related stigma clearly worked as either barriers to or facilitators of treatment which may influence the perception of BoT. Others were considered responsible for triggering a more complex cycle of burden.

\author{
"Treatment burden encompassed a cyclical aspect. For example, contradictory advice \\ on treatment by health care professionals (health care access burden) could lead to \\ polypharmacy (medication burden), which could then result in both a requirement for
}


339 extra time to organise medications (time burden) and extra strain on financial 340 resources (financial burden)" [7].

341

342 However, it is important to highlight that Environmental Factors were not just acting as 343 triggers, barriers or facilitators, but were also negatively affected by the treatment. An 344 example commonly found in the included studies was the negative impact of treatment

Participation (particular interpersonal relationships).

"The ability to overcome fear and manage symptoms varies between individuals, with less distress expressed in situations of self-confidence" [16]. 
"I'm too old now, that dialysis thing is more for younger people... Not for me" [14].

364

365 Finally, treatment regimens can also be seen to negatively influence Personal Factors.

366 Adhering to complex and potentially stigmatising treatment regimes, as well as the

367 tendency for people to be viewed as "patients" rather than "individuals" may directly

368 influence patients' self-identity:

369 sense of normality, was described by patients as reasons not to adhere:

376

377

"The parameters of normality in patients with PCD (Primary Ciliary Dyskinesia) are developed through experiences, achievements, expectations and comparison with healthy peers" [16].

The impact of treatment on Personal Factors, such as individual priorities, preferences or 
385

386

387

388

389

390

391

392

393

394

395

396

397

398

399

400

401

402

403

404

405

406

407

408

"Patients' treatment adherence behaviour is to some extent a product of rational decisions by the patient after contemplating perceived benefits and weighing them against perceived risks."(...) "Instances of non-adherence take place even when patients are aware of direct immediate negative consequences" [6].

The concept of burden of treatment and the ICF categories: content analysis following the ICF linking rules

There was substantial inter-rater agreement for the initial coding (ICF component: $k=0.748$, $95 \% \mathrm{Cl}=0.71$ to $0.792 ; 1^{\text {st }}$ t level: $k=0.811,95 \% \mathrm{Cl}=0.768$ to $0.854 ; 2^{\text {nd }}$ level: $\mathrm{k}=0.744,95 \% \mathrm{Cl}=$ 0.697 to $0.791 ; 3^{\text {rd }}$ level: $\mathrm{k}=0.715,95 \% \mathrm{Cl}=0.620$ to 0.805$)$.

The thematic analysis of the studies included in this review (described above) generated 179 subthemes. Using the ICF linking rules [9], these subthemes were coded to 77 ICF categories: 36 of which refer to the Body Functions and Structures, 19 to the Activities and Participation, and 22 to the Environmental Factors (table 2). Only the $1^{\text {st }}$ and $2^{\text {nd }}$ level categories are presented in table 2 , when a $3^{\text {rd }}$ level category was agreed, the equivalent $2^{\text {nd }}$ level was selected.

Inset stable 2 about here

Additionally, 44 meaningful concepts emerged from the second stage of the analysis and were not possible to link to a specific ICF category. These included 33 Personal Factors (which have not yet been classified by the ICF) and 11 'not-covered' concepts by the ICF, 
409 identified as "nc". Tables 3 and 4 list all Personal Factors and concepts identified as "nc", 410 respectively. A table with a list of subthemes, its meaningful concepts and the 411 corresponding ICF codes is available on Appendix 1.

412

Insert tables 3 and 4 about here

\section{Discussion}

416 The present systematic review and best-fit analysis is, to our knowledge, the first to explain 417 the concept of BoT using the standardised ICF terminology. The content analysis generated 418 lists of ICF categories (tables 2 to 4 ) that form the first list of candidate categories of a future 419 ICF Core Set for BoT. These findings represent a robust base of knowledge that can now 420 inform and be complemented with further studies of the preliminary phase of the 421 development of a Comprehensive ICF Core Set [20], namely qualitative studies and expert 422 surveys using our findings as a framework.

423

424 BoT has been shown to impact negatively on Body Functions and Structures and restrict 425 valued Activities and Participation, life roles and self-identity. Environmental and Personal 426 Factors were shown to shape the experience of BoT. For instance, strong family support can 427 reduce the perception of burden; similarly lack of appropriate equipment can increase the 428 perceived BoT. Conversely, BoT can also impact on Personal and Environmental Factors such 429 as when treatment obligations have a negative impact on family relationships and family 430 support. This description of BoT using the ICF terminology can be linked to previous studies 431 exploring the concept of BoT, as it has been described a biographical (self-identity; Personal 
432 Factors), relational (Environmental Factors and Activities and Participation) and biological 433 (Body Functions and Structures) disruption [18].

434

435 The findings of this literature review also represent an important contribution for future 436 developments of the ICF itself. Our analysis found the current list of ICF categories 437 insufficient to fully describe BoT. Many fundamental BoT concepts such as "adherence", 438 "capacity" and "workload" $[3-5,18]$ are "not covered" by the ICF (table 4). This is, 439 nevertheless, an understandable finding, given that the concept of BoT post-dates the 440 development of the ICF framework. Other concepts such as "treatment goals" or "treatment 441 outcomes" were too general to be linked to the ICF and were coded as "not defined". 442 Additionally, many concepts where linked to Personal Factors which have not yet been 443 specified by the ICF, although BoT theory places a significant emphasis on how treatments 444 affect and are affected by people's personal identities [3]. This study has begun to delineate 445 and specify some of the important concepts under the component Personal Factors and 446 highlighted the importance of Contextual Factors in general. These have relevance beyond a 447 future ICF Core Set for BoT and can inform future developments of the ICF document itself 448 [9].

Strengths and limitations and future directions

451 BoT is a new concept which, authors have argued, has the potential to radically change the 452 way that interventions are prescribed and managed in the patient/professional relationship $453[3,18,21]$. However, BoT may be unfamiliar to many health professionals. By using the 454 uniform terminology of the ICF, this study enables health professionals to more readily 455 access a potentially complex [21], but highly relevant theory. 
457 This study has its limitations. Including only qualitative studies, which expressly used the 458 terms "Burden of Treatment" or "Treatment Burden" may have resulted in the exclusion of 459 studies which explore the concept but without using the same terminology. A further 460 limitation, common to all qualitative literature reviews, is that some of the information and 461 context provided by the original participants may have been excluded from the original 462 papers and therefore, lost to the secondary analysis. Lastly, the inclusion of all relevant 463 qualitative studies regardless of their quality may have influenced our findings.

464

465 This study sought to explore the links between BoT and the ICF across a range of conditions 466 and treatments. This was an appropriate approach for demonstrating the conceptual 467 similarities between the two models. However, this approach of combining conditions could 468 potentially lead to an infinite number of categories, especially in the component Body 469 Functions and Structures. As BoT research progresses into more conditions it may become 470 more appropriate to incorporate the important BoT factors into the condition specific Core 471 Sets.

473 Future studies to complete the preparatory phase of a future ICF Comprehensive Core Set 474 for BoT are necessary. Qualitative research involving a range of stakeholders (patients, 475 healthcare professionals, policy-makers and caregivers) is needed. Furthermore, the need of 476 developing outcome measures of BoT has also been suggested in previous literature [4, 5];

477 the ICF could provide a useful framework for this. 
480 BoT impacts negatively on Body Functions and Structures and restricts valued Activities and 481 Participation, life roles and self-identity. Contextual Factors have a dual role both 482 influencing and being influenced by treatment burden. The use of ICF terminology to 483 describe BoT provides an accessible route for understanding this concept which although 484 complex is pivotal for rethinking clinical practice. This may lead to recognition that BoT is an 485 important consideration for treatment plans and patient adherence. Additional studies are 486 also necessary complete the preparatory phase of development of a future Comprehensive 487 ICF Core Set for BoT.

488

Declaration of interest

491 The authors report no declarations of interest.

\section{Reference List}

[1] Fried TR, Bradley EH. What Matters to Seriously III Older Persons Making End-of-Life

[2] Sawicki GS, Sellers DE, Robinson WM. High treatment burden in adults with cystic fibrosis: challenges to disease self-management. J Cyst Fibros 2009; 8: 91-6. Services Research 2014; 14: 1-11. 
503 [4] Eton DT, Ramalho de Oliveira D, Egginton JS, Ridgeway JL, Odell L, et al. Building a 504 measurement framework of burden of treatment in complex patients with chronic 505 conditions: a qualitative study. Patient Relat Outcome Meas 2012; 3: 39-49.

506 [5] Gallacher K, May CR, Montori, VM, Mair FS. Understanding patients' experiences of 507 treatment burden in chronic heart failure using normalization process theory. Ann Fam $508 \quad$ Med 2011; 9: 235-43.

509 [6] Karamanidou C, Weinman J, Horne R. A qualitative study of treatment burden among 510 haemodialysis recipients. J Health Psychol 2014; 19: 556-69.

511 [7] Sav A, Kendall E, McMillan SS, Kelly F, Whitty JA et al., 'You say treatment, I say hard 512 work': treatment burden among people with chronic illness and their carers in Australia. $513 \quad$ Health Soc Care Community 2013; 21: 665-74.

514 [8] Jordan S, Philpin S, Warring J, Cheung WY, Williams J. Percutaneous endoscopic 515 gastrostomies: the burden of treatment from a patient perspective. J Adv Nurs 2006; 56 : $516 \quad 270-81$

517 [9] Cieza A, Geyh S, Chatterji S, Kostanjsek N, Ustun G, et al. ICF linking rules: an update 518 based on lessons learned. J Rehabil Med 2005; 37: 212-8.

519 [10] World Health Organisation, International Classification of Functioning, $1^{\text {st }}$ ed: Geneva: $520 \quad$ Disability and Health; 2001.

521 [11] Stamm TA, Cieza A, Machold K, Smolen J, Stucki G. Exploration of the link between 522 conceptual occupational therapy models and the International Classification of 
523 Functioning, Disability and Health. Australian Occupational Therapy Journal 2006; 53: 9$524 \quad 17$.

525 [12] Baylor CR, Yorkston KM, Eadie TL, Maronian NC. The psychosocial consequences of 526 BOTOX injections for spasmodic dysphonia: a qualitative study of patients' experiences. J $527 \quad$ Voice 2007; 21: 231-47.

528 [13] George M, Rand-Giovannetti D, Eakin MN, Borrelli B, Zettler M, et al., Perceptions of 529 barriers and facilitators: self-management decisions by older adolescents and adults with 530 CF. J Cyst Fibros 2010; 9: 425-32.

531 [14] Johnston S, Noble H. Factors influencing patients with stage 5 chronic kidney disease to 532 opt for conservative management: a practitioner research study. J Clin Nurs 2012; 21: $533 \quad 1215-22$.

534 [15] Lewis CP, Newell JN. Improving tuberculosis care in low income countries - a qualitative 535 study of patients' understanding of "patient support" in Nepal. BMC Public Health 2009; 9: $536 \quad 1-9$.

537 [16] Schofield LM, Horobin HE. Growing up with Primary Ciliary Dyskinesia in Bradford, UK: 538 exploring patients experiences as a physiotherapist. Physiother Theory Pract 2014; 30 : $539 \quad 157-64$.

540 [17] Jani B, Blane D, Browne S, Montori V, May C, et al. Identifying treatment burden as an 541 important concept for end of life care in those with advanced heart failure. Curr Opin $542 \quad$ Support Palliat Care 2013; 7: 1-5. 
543 [18] Demain S, Goncalves AC, Areia C, Oliveira R, Marcos AJ et al. Living with, managing and

544 minimising treatment burden in long term conditions: a systematic review of qualitative $545 \quad$ research. PLoS One 2015; 10: 1-18.

546 [19] World Health Organisation, How to use the ICF: A practical manual for using the 547 International Classification of Functioning, Disability and Health (ICF). Exposure draft for 548 comment. Geneva: WHO; 2013.

549 [20] Selb M, Escorpizo R, Kostanjsek N, Stucki G, Ustun B, et al. A guide on how to develop 550 an International Classification of Functioning, Disability and Health Core Set. European 551 Journal of Physical and Rehabilitation Medicine 2015; 51: 105-117.

552 [21] Shippee ND, Shah ND, May CR, Mair FS, Montori VM. Cumulative complexity: a 553 functional, patient-centered model of patient complexity can improve research and $554 \quad$ practice. J Clin Epidemiol 2012; 65: 1041-51.

555 [22] Eton DT, Elraiyah TA, Yost KJ, Ridgeway JL, Johnson A, et al. A systematic review of 556 patient-reported measures of burden of treatment in three chronic diseases. Patient $557 \quad$ Relat Outcome Meas 2013; 4: 7-20.

558 [23] Liberati A, Altman DG, Tetzlaff J, Mulrow C, Gotzsche PC, et al., The PRISMA statement 559 for reporting systematic reviews and meta-analyses of studies that evaluate health care $560 \quad$ interventions: explanation and elaboration. PLoS Med 2009; 6: 1-28.

561 [24] Dixon-Woods M. How can systematic reviews incorporate qualitative research? A 562 critical perspective. Qualitative Research 2006; 6: 27-44. 
563 [25] CASP [Internet]. Critical appraisal skills programme - Qualitative Checklist. 2013 [cited 564 2014]; Available from: http://www.casp-uk.net/\#!casp-tools-checklists/c18f8.

565 [26] Dixon-Woods, M. Using framework-based synthesis for conducting reviews of 566 qualitative studies. BMC Med 2011; 9: 1-2.

567 [27] Carroll C, Booth A, Cooper K. A worked example of "best fit" framework synthesis: a 568 systematic review of views concerning the taking of some potential chemopreventive 569 agents. BMC Med Res Methodol 2011; 11: 1-9.

570 [28] Gallacher K, Morrison D, Jani B, McDonald S, May C, et al. Uncovering treatment burden 571 as a key concept for stroke care: a systematic review of qualitative research. PLoS Med $572 \quad 2013 ; 10: 1-17$

[29] Gallacher K, Jani B, Morrison D, McDonald S, Blane D, et al. Qualitative systematic 574 reviews of treatment burden in stroke, heart failure and diabetes - Methodological 575 challenges and solutions. BMC Medical Research Methodology 2013; 13: 1-10.

576 [30] Ibragimova NK, Pless M, Adolfsson M, Granlund M, Bjorck-Akesson E. Using content 577 analysis to link texts on assessment and intervention to the International Classification of 578 Functioning, Disability and Health - version for Children and Youth (ICF-CY). J Rehabil Med $579 \quad 2011 ; 43: 728-33$.

580 [31] Elliott AC, Woodward WA. Statistical Analysis - Quick Reference Guidebook. $1^{\text {st }}$ Ed. 581 California - United States of America: SAGE Publications; 2007.

582 [32] Landis JR, Koch GG. The Measurement of Observer Agreement for Categorical Data. $583 \quad$ Biometrics 1977; 33: 159-174. 
584 [33] Alansari R, Bedos C, Allison P. Living with cleft lip and palate: the treatment journey. 585 Cleft Palate Craniofac J 2014; 51: 222-9.

586 [34] Hyland ME, Whalley B, Jones RC, Masoli M. A qualitative study of the impact of severe 587 asthma and its treatment showing that treatment burden is neglected in existing asthma 588 assessment scales. Qual Life Res, 2014; 0: 1-9.

589 [35] Kahn LS, Vest BM, Madurai N, Singh R, York TRM et al. Chronic kidney disease (CKD) 590 treatment burden among low-income primary care patients. Chronic IIIn 2014; 0: 1-13.

591 [36] LeBovidge JS, Haskell S, Olney E, Hoyte L, Rachid R, et al. The psychological impact of 592 oral immunotherapy for children with food allergy: Perceived benefits and treatment $593 \quad$ burden. Clinical Practice in Pediatric Psychology 2014; 2: 13-26.

594 [37] Ridgeway JL, Egginton JS, Tiedje K, Linzer M, Boehm D, et al., Factors that lessen the 595 burden of treatment in complex patients with chronic conditions: a qualitative study. $596 \quad$ Patient Prefer Adherence 2014; 8: 339-51.

597 [38] Sawicki GS, Heller KS, Demars N, Robinson WM. Motivating adherence among 598 adolescents with cystic fibrosis: Youth and parent perspectives. Pediatr Pulmonol 2014; 0: $599 \quad 1-10$. 


\section{Page 79 of 110}

Disability and Rehabilitation

600

URL: http:/mc.manuscriptcentral.com/dandr Email: davemuller@suffolk.ac.uk 


\section{Implications for rehabilitation}

- Health professionals applying the ICF should consider the negative impact of interventions on patient's life roles and self-identity, Body Functions and Structures and on valued Activities and Participation.

- Health professionals who may be concerned about the treatment burden being experienced by their patients can now use the ICF terminology to discuss this with the multidisciplinary team.

- Poor adherence to rehabilitation programmes may be explained by an increased burden of treatment. This phenomenon can now be mapped to the ICF, and coded using a framework well known by multidisciplinary teams. 
Figure 1. Study selection process. $169 \times 160 \mathrm{~mm}$ ( $300 \times 300$ DPI) 


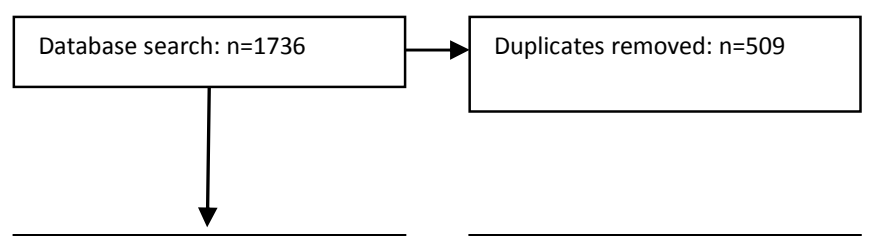

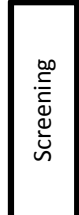

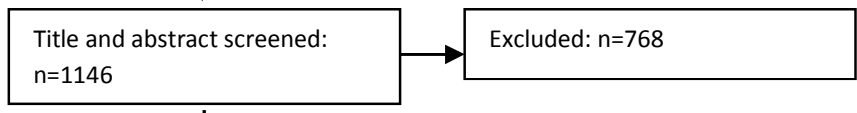

Included: $\mathrm{n}=17$ $\frac{0}{d}$
$\frac{0}{3}$
$\frac{U}{\leq}$

Full text exclude: $n=361$

(Not relevant: $n=194$ )

(Not qualitative: $n=167$ )

Figure 1. Study selection process.

Font: Calibri (Body)

URL: http:/mc.manuscriptcentral.com/dandr Email: davemuller@suffolk.ac.uk 
Table 1. Characteristics of the included studies.

\begin{tabular}{|c|c|c|c|c|c|}
\hline Study & Age range & Health condition & n & $\begin{array}{l}\text { Qualitative data } \\
\text { collection methods }\end{array}$ & Country \\
\hline Alansari et al., 2014 [33] & $18-60$ & cleft lip and palate & 11 & Interviews & Canada \\
\hline \multirow[t]{2}{*}{ Baylor et al., 2007 [12] } & $49-80$ & Spasmodic & 6 & Interviews & USA \\
\hline & & Dysphonia & & & \\
\hline Eton et al., 2012 [4] & $26-85$ & Multi pathologies & 32 & Interviews & USA \\
\hline Fried et al., 2003 [1] & $\begin{array}{l}\text { (mean = } \\
70)\end{array}$ & $\begin{array}{l}\text { Chronic diseases } \\
\text { (end of life) }\end{array}$ & 23 & FG and interviews & USA \\
\hline Gallacher et al., 2011 [5] & $45-88$ & $\begin{array}{l}\text { Chronic Heart } \\
\text { Failure }\end{array}$ & 47 & $\begin{array}{l}\text { Interviews (secondary } \\
\text { analysis) }\end{array}$ & UK \\
\hline George et al., 2010 [13] & $16-35$ & Cystic Fibrosis & 25 & Interviews & USA \\
\hline Hyland et al., 2014 [34] & $28-70$ & Severe asthma & 23 & Interviews & UK \\
\hline Johnston and Noble, 2012 [14] & $74-96$ & $\begin{array}{l}\text { Chronic kidney } \\
\text { Disease }\end{array}$ & 9 & Interviews & UK \\
\hline Jordan et al., 2006 [8] & $24-84$ & $\begin{array}{l}\text { Percutaneous } \\
\text { Endoscopic } \\
\text { Gastrostomies }\end{array}$ & 20 & $\begin{array}{l}\text { Mixed methods } \\
\text { (interviews and QoL } \\
\text { measure) }\end{array}$ & UK \\
\hline Kahn et al., 2014 [35] & $\begin{array}{l}(\text { mean }= \\
61.7)\end{array}$ & $\begin{array}{l}\text { Chronic kidney } \\
\text { disease }\end{array}$ & 34 & Interviews & USA \\
\hline Karamanidou et al., 2014 [6] & $32-68$ & Renal Disease & 7 & Interviews & Greece \\
\hline LeBovidge et al., 2014 [36] & $\begin{array}{l}\text { Study 1: 9- } \\
18 \\
\text { Study 2: 7- } \\
15\end{array}$ & Food allergies & $\begin{array}{l}\text { Study 1: } 10 \\
\text { children + } 9 \\
\text { parents; } \\
\text { Study 2: } 13 \\
\text { children + } 13 \\
\text { parents }\end{array}$ & Interviews & USA \\
\hline Lewis and Newell, 2009 [15] & $\begin{array}{l}\text { Not } \\
\text { mentioned }\end{array}$ & Tuberculosis & 23 & FG and interviews & Nepal \\
\hline Ridgeway et al., 2014 [37] & $26-87$ & Chronic diseases & 75 & FG and interviews & USA \\
\hline Sav et al., 2013 [7] & $16-83$ & Chronic diseases & 97 & Interviews & Australia \\
\hline Schofield and Horobin, 2014 [16] & $8-15$ & $\begin{array}{l}\text { Primary Ciliary } \\
\text { Dyskinesia }\end{array}$ & 5 & Interviews & UK \\
\hline Sawicki et al., 2014 [38] & $16-21$ & Cystic Fibrosis & 18 & Interviews & USA \\
\hline
\end{tabular}


Table 1. Burden of treatment concept linked to the ICF categories.

\begin{tabular}{|c|c|c|}
\hline ICF Code & ICF category title & Studies \\
\hline \multicolumn{3}{|c|}{ Body Functions } \\
\hline b126 & Temperament and personality functions & [34] \\
\hline b130 & Energy and drive functions & {$[6,8,12,13,15,16]$} \\
\hline b134 & Sleep functions & {$[4,34]$} \\
\hline b152 & Emotional functions & {$[1,4,5,8,12,13,16,34,36]$} \\
\hline b210 & Seeing functions & {$[4]$} \\
\hline b240 & Sensations associated with hearing and vestibular function & {$[36]$} \\
\hline b280 & Sensation of pain & {$[1,4,6,12,33-36]$} \\
\hline b310 & Voice functions & {$[12,16]$} \\
\hline b420 & Blood pressure functions & [35] \\
\hline b435 & Immunological system functions & {$[6,8,36]$} \\
\hline b440 & Respiration functions & {$[1,13]$} \\
\hline b450 & Additional respiratory functions & {$[6,13,16,34]$} \\
\hline b455 & Exercise tolerance functions & {$[1,4,6,12,16,33-35,38]$} \\
\hline b460 & Sensations associated with cardiovascular and respiratory functions & {$[6,12,13,16,34,36]$} \\
\hline b510 & Ingestion functions & {$[8,12,34,36]$} \\
\hline b515 & Digestive functions & [8] \\
\hline b525 & Defecation functions & {$[34]$} \\
\hline b530 & Weight maintenance functions & {$[34,37]$} \\
\hline b610 & Urinary excretory functions & {$[6]$} \\
\hline b620 & Urination functions & {$[35]$} \\
\hline b7 & Neuromusculoskeletal and movement related functions & {$[8,34]$} \\
\hline b780 & Sensations related to muscles and movement functions & [12] \\
\hline b8 & Functions of the skin and related structures & {$[6,34,36]$} \\
\hline \multicolumn{3}{|c|}{ Body Structures } \\
\hline s2 & The eye, ear and related structures & {$[4]$} \\
\hline s330 & Structure of pharynx & {$[16,36]$} \\
\hline s410 & Structure of cardiovascular system & {$[6,16]$} \\
\hline s430 & Structure of respiratory system & {$[1,12,13,16,36]$} \\
\hline s530 & Structure of stomach & {$[8,34,36]$} \\
\hline s540 & Structure of intestine & {$[34]$} \\
\hline s610 & Structure of urinary system & {$[6,35]$} \\
\hline s7 & Structures related to movement & {$[34]$} \\
\hline s710 & Structure of head and neck region & {$[12]$} \\
\hline s720 & Structure of shoulder region & {$[6]$} \\
\hline s770 & Additional musculoskeletal structures related to movement & {$[12]$} \\
\hline s8 & Skin and related structures & {$[34]$} \\
\hline s810 & Structure of areas of skin & {$[6]$} \\
\hline \multicolumn{3}{|c|}{ Activities and Participation } \\
\hline d1 & Learning and applying knowledge & {$[4-8,12]$} \\
\hline $\mathrm{d} 230$ & Carrying out daily routine & {$[5,6,13,35,37,38]$} \\
\hline $\mathrm{d} 240$ & Handling stress and other psychological demands & {$[12,33]$} \\
\hline d3 & Communication & {$[4-6,14]$} \\
\hline d330 & Speaking & {$[12]$} \\
\hline d4 & Mobility & {$[8]$} \\
\hline d455 & Moving around & {$[13,16]$} \\
\hline $\mathrm{d} 470$ & Using transportation & {$[5]$} \\
\hline d5 & Self-care & {$[7,12,14,16,35,37,38]$} \\
\hline d550 & Eating & {$[4,8]$} \\
\hline d570 & Looking after one's health & {$[4,5,13,37,38]$} \\
\hline d620 & Acquisition of goods and services & {$[37,38]$} \\
\hline d7 & Interpersonal interactions and relationships & {$[4-8,12,14,33,35,37,38]$} \\
\hline d8 & Major life areas & {$[8,12,13,38]$} \\
\hline d850 & Remunerative employment & {$[4,5,7,12,13,38]$} \\
\hline d855 & Non-remunerative employment & [8] \\
\hline d9 & Community, social and civic life & {$[5,12,36,38]$} \\
\hline d920 & Recreation and leisure & {$[4,7,8,13,16,36,38]$} \\
\hline d930 & Religion and spirituality & {$[35]$} \\
\hline Environme & Factors & \\
\hline
\end{tabular}


[8]

e1 Products and technology [8]

e110 Products or substances for personal consumption

e115 Products and technology for personal use in daily living

Time-related changes

e3 Support and relationships

e310 Immediate family

e315 Extended family

e320 Friends

e325 Acquaintances, peers colleagues, neighbours and community members

e355 Health professionals

e4 Attitudes

e410 Individual attitudes of immediate family members

e415 Individual attitudes of extended family members

e420 Individual attitudes of friends

e425 Individual attitudes of acquaintances, peers colleagues, neighbours and community members

Individual attitudes of health professionals

Societal attitudes

$[4,5,7,37,38]$

$[1,4,5,7,8,13,35,37]$

[16]

$[4-6,8,12,14,33,38]$

$[5,12-16,35,37,38]$

$[5,12,14-16,35,37,38]$

$[4,5,35,37]$

$[6,12,13,15,35,37]$

$[5-8,12-15,33,35,37,38]$

$[6-8,12,13,15,16,33,38]$

$[5,12-16,35,37,38]$

$[5,12,14-16,35,37]$

$[4,5,12,35,37]$

$[12,13,15,35,37]$

$[4-8,12-15,33,35,37,38]$

[16]

[7]

$[5]$

$[5,7,14,35]$

$[4-8,12-16,35,37,38]$ $[7,13]$

The ICF codes starting with "b", "s", "d" and "e" indicate the components: "body functions" (b), "body structures" (s), "activities and participation" (d) and "environmental factors" (e). 
Table 1. Meaningful concepts linked to the Personal Factors.

\begin{tabular}{|c|c|}
\hline Personal Factors & Studies \\
\hline Age & {$[1,6,7,12-14,33,38]$} \\
\hline Being active & {$[6,15]$} \\
\hline Beliefs about illness and treatment & {$[1,5,6,12,14-16,38]$} \\
\hline Coping strategies & {$[4-7,12,16,37]$} \\
\hline Desire to avoid being a burden & {$[1,14]$} \\
\hline Discipline & {$[13]$} \\
\hline Disease acceptance & {$[6,8,16]$} \\
\hline Employment & {$[4,13,35]$} \\
\hline Empowerment & {$[6,13-16,33,37,38]$} \\
\hline Ethnicity and religion & {$[4,7,13]$} \\
\hline Family context & {$[12,14,35]$} \\
\hline Fears & {$[4,5,12,36]$} \\
\hline Feeling isolated & {$[15,33]$} \\
\hline Financial Context & {$[4,5,7,35]$} \\
\hline Gender & {$[4,13]$} \\
\hline Hope and Faith & {$[6,35,37]$} \\
\hline Individual judgements / decisions or choices & {$[1,6,7,12-14,16,33,35,38]$} \\
\hline Individual needs / characteristics & {$[4-7,12-14,16,33]$} \\
\hline Knowledge/ Education & {$[4-7,12,13,15,16,35,38]$} \\
\hline Life experiences & {$[12,16]$} \\
\hline Life style & {$[12,13]$} \\
\hline Marital status & {$[4,13]$} \\
\hline Not feeling capable & {$[5,14]$} \\
\hline Organisation skills & {$[4,5,37,38]$} \\
\hline Perception of own health status & {$[4,14,16]$} \\
\hline Perception of quality of life (coded as not defined - quality of life) & {$[1,6,38]$} \\
\hline Positive/Negative mental attitude & {$[6,8,12,13,15,16]$} \\
\hline Treatment Preferences & {$[1,4,13,16,35,37,38]$} \\
\hline Priorities and Life goals & {$[13,38]$} \\
\hline Resilience & {$[4-8,12,16,33,35]$} \\
\hline Self-confidence and motivation & {$[6,13,15,16,33,35,37]$} \\
\hline Self-image & {$[6,7,12,13,16,33,38]$} \\
\hline Sense of normality & {$[6,12,13,16,33,36-38]$} \\
\hline
\end{tabular}


2

Table 1. Meaningful concepts identified as not covered by the ICF

\begin{tabular}{ll}
\hline Concepts not covered by the ICF & Studies \\
Adherence/Non-adherence to treatment & {$[1,4-7,12-16,33,35,37,38]$} \\
Absence of empowerment & {$[6,15,16]$} \\
Burdens to others & {$[14]$} \\
Capacity & {$[4,5,7,8,12,14,16]$} \\
Discharge process & {$[8]$} \\
Time frame / time burden & {$[1,4,5,7,8,13,14,16]$} \\
Treatment regimen & {$[1,4-8,12-16,33-38]$} \\
Workload & {$[4,5,7,12-14,35,38]$} \\
Work needed to adjust the requirements imposed by treatment & {$[5,7,12]$} \\
Performing more than one activity at the same time & {$[16]$} \\
Sputum production & {$[16]$} \\
\hline
\end{tabular}


Supplementary file: Content analysis linking subthemes emerged from the framework synthesis to the ICF

\begin{tabular}{|c|c|c|}
\hline \multicolumn{3}{|l|}{ Theme 1:Environmental factors } \\
\hline Subtheme & Meaningful concepts & ICF codification \\
\hline 1.1 Architectural barriers & Architectural barriers & e515 \\
\hline \multirow{2}{*}{$\begin{array}{l}1.2 \text { Positive and negative communication aspects with } \\
\text { health care professionals }\end{array}$} & Positive and negative aspects of communication & d3 \\
\hline & Health professionals & e355; e450 \\
\hline \multirow[t]{2}{*}{ 1.3 Complex treatment regimens } & Complexity (related to health care services) & e5800 \\
\hline & Treatment regimens & nc \\
\hline 1.4 Difficult to access to health care & Difficult to access to health care & e580 \\
\hline \multirow[t]{2}{*}{ 1.5 Engaging with $\mathrm{HCP}$} & Health care professionals & e355; e450 \\
\hline & Activity of engaging with others in a health care context & $d 5 ; d 7$ \\
\hline \multirow[t]{3}{*}{ 1.6 Family, friends \& co-workers (social network) } & Family & e310; e410; e315; e415 \\
\hline & Friends & e320; e420; \\
\hline & Co-workers & e325; e425 \\
\hline \multirow[t]{2}{*}{ 1.7 Financial burden caused by health related costs } & Financial context & $\mathrm{pf}$ \\
\hline & Health related costs & d5; e580 \\
\hline \multirow[t]{2}{*}{ 1.8 Good health policies or services } & Health care policies & e580; e5802 \\
\hline & Health care services & e580; e5800 \\
\hline
\end{tabular}




\section{Page 89 of 110}

Disability and Rehabilitation

\begin{tabular}{|c|c|c|}
\hline \multirow[t]{3}{*}{1.9 Individualised treatment methods } & Individual needs & $\mathrm{pf}$ \\
\hline & Treatment regimens & nc \\
\hline & Health services (provision of care) & e580 \\
\hline 1.10 Lack of continuity and integrated health services & Health services systems and policies & e580 \\
\hline \multirow[t]{2}{*}{ 1.11 No supported discharge } & Health services systems and policies (regarding discharge process) & e580 \\
\hline & Discharge process & nc \\
\hline 1.12 Polyphaymacy & Polyphaymacy & e110 \\
\hline 1.13 Positive aspects of treatment & Health services (provision of care) & e5800 \\
\hline \multirow{2}{*}{$\begin{array}{l}1.14 \text { Positive and negative impact of treatment on } \\
\text { relationships }\end{array}$} & Positive and negative impact & nd \\
\hline & Relationships & e3; e7 \\
\hline \multirow{3}{*}{$\begin{array}{l}1.15 \text { Side effects or other negative consequences of } \\
\text { treatment }\end{array}$} & Side effects and other negative consequences & nd \\
\hline & Treatment regimen & $\mathrm{nc}$ \\
\hline & Health services (provision of care) & e5800 \\
\hline 1.16 Stigma & Stigma & e460 \\
\hline \multirow[t]{3}{*}{ 1.17 Time and travelling burden (related to treatment) } & Travelling & e540; d470; d475 \\
\hline & Time frame / time burden & nc \\
\hline & Health services & e580 \\
\hline 1.18 Treatment related equipment as facilitators of & Treatment related equipment & e115 \\
\hline
\end{tabular}

URL: http:/mc.manuscriptcentral.com/dandr Email: davemuller@suffolk.ac.uk 
treatment and prompts of adherence

Adherence

Unhelpful Health care professionals

Treatment regimen

Non-effective provision of care

Peer support

1.21 Having peer support

1.19 Unhelpful Health care professionals

1.20 Unsuccessful or without benefit treatments
Theme 2: Environmental Factors linked to Personal Factors

Subtheme

2.1 Absence of empowerment to undertake and be more active in the treatment

6
8
9
0
1
2
3
4
5
6
7
8
9
0
4
2
3
4
5
6
7
8

2.2 Adapting treatment regimens to individual needs
3355; e450

e5800

e325; e425
Meaningful concept

Empowerment; absence of empowerment

Being active

Treatment regimens

Treatment regimens

Individual needs

Age

Treatment decisions

Health services (provision of care)
ICF codification

pf; nc

pf

nc

pf

pf

pf; nc

e5800 


\begin{tabular}{|c|c|c|}
\hline $\begin{array}{l}2.4 \text { The assessment of effectiveness considers personal } \\
\text { factors }\end{array}$ & Assessment of effectiveness & $\mathrm{pf}$ \\
\hline \multirow[t]{2}{*}{2.5 Avoiding to be a burden to others } & Being a burden to others & $\mathrm{nc}$ \\
\hline & Desire to avoid being a burden & $\mathrm{pf}$ \\
\hline \multirow{2}{*}{$\begin{array}{l}2.6 \text { Co-existing health conditions reduce capacity to } \\
\text { adhere }\end{array}$} & Co-existing health conditions & hc \\
\hline & capacity & $\mathrm{nc}$ \\
\hline \multirow{2}{*}{ 2.7 Confusion or lack of knowledge about the treatment } & Lack of knowledge & $\mathrm{pf}$ \\
\hline & Health services (provision of care) & e580 \\
\hline \multirow[t]{3}{*}{ 2.8 Day time preferences for treatment } & Preferences & $\mathrm{pf}$ \\
\hline & Time-related changes & e245 \\
\hline & Health services (provision of care) & e580 \\
\hline \multirow[t]{2}{*}{ 2.9 Ethnicity and religion affects the access to health care } & Ethnicity and religion & $\mathrm{pf}$ \\
\hline & Access to health care & e580 \\
\hline \multirow[t]{2}{*}{ 2.10 Family context influences the impact of treatment } & Family context & $\mathrm{pf}$ \\
\hline & Treatment regimen & $\mathrm{nc}$ \\
\hline 2.11 Fear and anxiety about treatment and treatment & Fear & $\mathrm{pf}$ \\
\hline
\end{tabular}


2.12 Feeling isolated due to treatment requirements, stigma or lack of knowledge

Feeling isolated

2.13 Life-style changes to fit treatment

Life style

pf

Treatment regimen

Individual needs

Health care professionals

Not feeling capable

nc

pf

e450; e355

pf

Treatment regimen

nc

Adherence

nc

Individual choices

pf

Perception of QoL

nd-qol

Treatment decisions

\section{pf}




\begin{tabular}{|c|c|c|}
\hline \multirow[t]{2}{*}{ 2.18 Personal beliefs about life and treatment } & Personal beliefs & $\mathrm{pf}$ \\
\hline & Treatment regimen & $\mathrm{nc}$ \\
\hline \multirow[t]{2}{*}{ 2.19 Poor confidence or motivation for treatment } & Self-confidence and motivation & pf; b130 \\
\hline & Treatment regimen & $\mathrm{nc}$ \\
\hline \multirow[t]{2}{*}{ 2.20 Positive mental attitude promoting adherence } & Positive mental attitude & $\mathrm{pf}$ \\
\hline & Adherence & $\mathrm{nc}$ \\
\hline \multirow[t]{2}{*}{ 2.21 Reluctance to approach health care professionals } & Reluctance/fear & $\mathrm{pf}$ \\
\hline & Health care professionals & e450; e355 \\
\hline \multirow{3}{*}{$\begin{array}{l}2.22 \text { Resilience about the disease and treatment } \\
\text { increases the capacity to adhere }\end{array}$} & Resilience & $\mathrm{pf}$ \\
\hline & Capacity & $\mathrm{nc}$ \\
\hline & Adherence & $\mathrm{nc}$ \\
\hline \multirow{3}{*}{$\begin{array}{l}2.23 \text { Self-image and sense of normality determines } \\
\text { treatment choices }\end{array}$} & Self-image & $\mathrm{pf}$ \\
\hline & Sense of normality & $\mathrm{pf}$ \\
\hline & Treatment choices & $\mathrm{pf}$ \\
\hline \multirow[t]{2}{*}{ 2.24 Self-care demands add workload to the treatment } & Self-care & d5 \\
\hline & Workload & $\mathrm{nc}$ \\
\hline
\end{tabular}


2.25 Treatment affecting all areas of life

2.26 Treatment choices change overtime

2.27 Inability to work limits capacity to pay for medication
All areas of life

Treatment regimen

Treatment choices

Time frame

Employment

Capacity

Medication

Perception of own health status

2.28 Discrepancy in perceptions of effort between health care professionals and patient

2.29 Having a routine as a strategy to reduce treatment workload and promote adherence

Health care professionals nd

nc

nc

pf; $d 850$

nc

e110

pf

e355; e450

d230

pf

nc

nc 


\begin{tabular}{|c|c|c|}
\hline Subtheme & Meaningful concept & ICF codification \\
\hline 3.1 Sports as treatment & sports & d9201 \\
\hline \multirow[t]{2}{*}{ 3.2 Leisure activities promoting adherence } & Leisure activities & d920 \\
\hline & Adherence & $\mathrm{nc}$ \\
\hline \multirow{2}{*}{$\begin{array}{l}\text { 3.3 Activity limitations lead to limitations on treatment } \\
\text { adherence }\end{array}$} & Activity limitations & nd \\
\hline & Adherence & $\mathrm{nc}$ \\
\hline \multirow[t]{2}{*}{ 3.4 Adapting treatment to fit activities } & Treatment regimen & $\mathrm{nc}$ \\
\hline & Activities & nd \\
\hline \multirow[t]{2}{*}{ 3.5 Choosing enjoying activities instead of treatment } & Individual choices & $\mathrm{pf}$ \\
\hline & Enjoying activities & d920 \\
\hline \multirow[t]{2}{*}{ 3.6 Costs of treatment limiting activities } & Treatment costs & e580 \\
\hline & Activities & nd \\
\hline 3.7 Learning about treatment & Learning & $\mathrm{d} 1 ; \mathrm{d} 5$ \\
\hline 3.8 Self-management activities & Self-management activities & d5 \\
\hline \multirow[t]{2}{*}{ 3.9 Treatment allowing activities } & Treatment regimen / outcomes & $\mathrm{nc}$ \\
\hline & Activities & nd \\
\hline
\end{tabular}


3.10 Treatment itself limiting activities

Treatment regimen / outcomes

Activities

workload

3.11 Workload by self-management activities influencing adherence

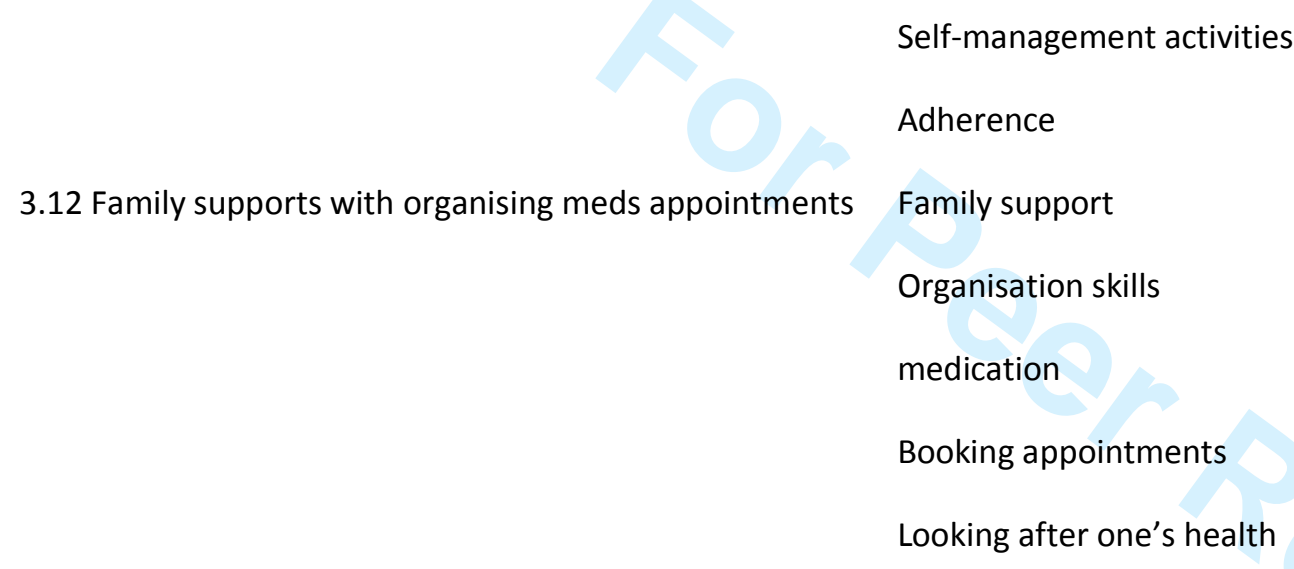

Self-management activities

d5

nc

e310; e315

pf; d230

e1101

d620

d570

\section{Theme 4: Environmental Factors linked to Participation}

\begin{tabular}{lll} 
Subtheme & Meaningful concept & \\
\hline 4.1 Actively seeking support from family and friends & Being active & Sf \\
& Support from family \\
& Support from friends \\
4.2 Costs of treatment stopping participation & Treatment costs
\end{tabular}


4.3 Employment hindering adherence

Participation

Employment

Adherence

Support from others

workload

4.5 Managing workload of treatment and participation in meaningful life activities

Participation in meaningful life activities

d8; d9

4.6 Participation restrictions triggering adherence

4.7 Treatment limiting or promoting social participation and leisure activities

\section{Participation restriction}

Adherence

Treatment regimen

Social participation and leisure activities

Treatment regimen

Sports

Treatment regimen

4.8 Treatment limiting or promoting sports participation

4.9 Treatment limiting or promoting employment and career development 
Theme 5: Environmental Factors linked to Body Functions and Structures

\begin{tabular}{|c|c|c|}
\hline Subtheme & Meaningful concept & ICF codification \\
\hline \multirow[t]{2}{*}{ 5.1 Treatment promotes coughing and lung clearance } & Treatment regimen & nc \\
\hline & Coughing and lung clearance & b450; b440; s4301 \\
\hline \multirow[t]{2}{*}{ 5.2 Dry skin due to treatment } & Dry skin & b8; s810 \\
\hline & Treatment regimen & nc \\
\hline \multirow{3}{*}{$\begin{array}{l}5.3 \text { Fatigue due to treatment, limiting treatment } \\
\text { adherence }\end{array}$} & Fatigue & b4452 \\
\hline & Treatment regimen & nc \\
\hline & Adherence & $\mathrm{nc}$ \\
\hline \multirow{2}{*}{$\begin{array}{l}5.4 \text { Voice symptoms improved by treatment or caused by } \\
\text { treatment }\end{array}$} & Voice related symptoms & b310; s3 \\
\hline & Treatment regimen & nc \\
\hline \multirow[t]{2}{*}{5.5 Infections due to treatment } & Infections & hc; b435 \\
\hline & Treatment regimen & $\mathrm{nc}$ \\
\hline \multirow[t]{2}{*}{ 5.6 Movement restrictions due to treatment } & Movement restrictions & b7; d4 \\
\hline & Treatment regimen & nc \\
\hline 5.7 Need of ventilator because of lung dysfunction & Ventilator & e115 \\
\hline
\end{tabular}


5.8 Not feeling well to use public transport

5.9 Pain or discomfort due to treatment

5.10 Physical limitations due to not well adapted treatment technologies

\subsection{Respiratory symptoms caused or reduced by} treatment

5.12 side effects

5.13 Sleep disorder due to medication

5. 14 Stigma of coughing leads to cough suppression

5.15 Stomach ulcers due to health care professionals lack of knowledge about treatment
Lung dysfunction

Not feeling well

Use public transport

Pain or discomfort

Treatment regimen

Physical limitations

Treatment technologies

Respiratory symptoms

\section{Treatment regimen}

b440; s4301

nd

d470; e530

b280

nc

nd

e1

b460; b450; s430

nc

\section{Side effects}

nd

\section{Sleep disorder}

b134

Medication

e110

e460

b450

b515; s530 
Health care professionals

e355; e450

5.16 Swallowing issues due to treatment

Swallowing issues

b5105

Treatment regimen

nc

Taking medication

e1101

\begin{abstract}
something
\end{abstract}
Body missing something

nd

Tight neck

s710

Treatment regimen

nc

Treatment regimen

nc of food into stomach

large volumes of food into stomach

s530; b515

\section{Theme 6: Personal Factors}

\section{Subtheme}

Meaningful concept

\section{ICF codification}

6.1 Age and gender

Age

Gender

6.2 Confidence and hope 


\begin{tabular}{|c|c|c|}
\hline 6.3 Discipline & Discipline & $\mathrm{pf}$ \\
\hline 6.4 Disease acceptance & Disease acceptance & $\mathrm{pf}$ \\
\hline 6.5 Employment & Employment & pf; d850 \\
\hline 6.6 Empowerment & Empowerment & $\mathrm{pf}$ \\
\hline \multirow[t]{2}{*}{ 6.7 Ethnicity and marital status } & Ethnicity & $\mathrm{pf}$ \\
\hline & Marital status & $\mathrm{pf}$ \\
\hline 6.8 Fears & Fears & pf; b152 \\
\hline 6.9 Health status & Perception of own health status & $\mathrm{pf}$ \\
\hline \multirow[t]{2}{*}{6.10 Individual needs and preferences } & Individual needs & $\mathrm{pf}$ \\
\hline & Individual preferences & $\mathrm{pf}$ \\
\hline \multirow[t]{2}{*}{ 6.11 Knowledge about disease and treatment } & Knowledge & pf; d1 \\
\hline & Treatment regimen & $\mathrm{nc}$ \\
\hline \multirow[t]{2}{*}{ 6.12 Life style and life experiences } & Life style & $\mathrm{pf}$ \\
\hline & Life experiences & $\mathrm{pf}$ \\
\hline 6.13 Motivation & Motivation & $\mathrm{pf}$ \\
\hline 6.14 sense of normality & sense of normality & $\mathrm{pf}$ \\
\hline 6.15 Personal believes & Personal believes & $\mathrm{pf}$ \\
\hline
\end{tabular}


6.16 Positive and negative feelings

Positive and negative feelings

pf; b152

6.17 Resilience and coping strategies

Resilience

$\mathrm{pf}$

coping strategies

pf

Education

pf

6.18 Years of formal education

Religion and faith

pf; $d 930$

6.19 Religion and faith

Life goals

pf

Theme 7: Personal Factors linked to Activities

Subtheme

Meaningful concept

ICF codification

7.1 Imbalance between workload and capacity

Workload

nc

Capacity

nc

7.2 Incorporate treatment in routine

Treatment regimen

nc

Routine

d230

7.3 Organisation skills to manage treatment

Organisation skills

pf; d230

Treatment regimen

$\mathrm{nc}$

7.4 Positive attitudes associated to activities

Positive attitudes

pf; b152

Activities

nd 
Theme 8: Personal Factors linked to Participation

\begin{tabular}{|c|c|c|}
\hline Subtheme & Meaningful concept & ICF codification \\
\hline 8.1 Fears limiting adherence & $\begin{array}{l}\text { Fears } \\
\text { Adherence }\end{array}$ & $\begin{array}{l}\text { pf; b152 } \\
\text { nc }\end{array}$ \\
\hline 8.2 Personal priorities and career & $\begin{array}{l}\text { Personal priorities } \\
\text { career }\end{array}$ & $\begin{array}{l}\text { pf; d850 } \\
\text { pf; d850 }\end{array}$ \\
\hline \multicolumn{3}{|c|}{ Theme 9: Personal Factors linked to Body Functions and Structures } \\
\hline Subtheme & Meaningful concept & ICF codification \\
\hline \multirow[t]{3}{*}{9.1 Coping strategies for stress and pain } & Coping strategies & $\mathrm{pf}$ \\
\hline & Stress & $d 240$ \\
\hline & pain & b280 \\
\hline \multirow[t]{2}{*}{ 9. 2 Fear of having a needle in the throat } & fear & pf; b152 \\
\hline & throat & s3 \\
\hline \multirow{2}{*}{$\begin{array}{l}\text { 9.3 Treatment goals change according to its effects on } \\
\text { voice }\end{array}$} & Treatment goals & nd \\
\hline & Effects on voice & s3; b310 \\
\hline 9.4 Knowledge about respiratory system & Knowledge & pf; d1 \\
\hline
\end{tabular}


9.5 Perception of QoL changes with perception of fatigue Perception of QoL

nd-qol

Fatigue

b4552

9.6 Personal characteristics influencing perceptions of

Personal characteristics

pf respiratory symptoms

respiratory symptoms

b450; b460

9.7 Respiratory symptoms reducing motivation

respiratory symptoms

b450; b460

Motivation

pf; b130

9.8 Symptoms influencing self-image

Symptoms

nd

self-image

pf

Symptoms

nd

Sense of normality

9.10 Balancing BoT and treatment outcomes

Balancing BoT

nd; nc

treatment outcomes

nd

\section{Theme 10: Activities}

\section{Subtheme}

Meaningful concept

ICF codification

10.1 Speaking

d330 


$\begin{array}{lll}\text { 10.2 Disease limiting eating } & \text { Disease } & \mathrm{hc} \\ & \text { Eating } & \mathrm{d} 550 \\ \text { 10.3 Running } & \text { Running } & \mathrm{d} 455 \\ 10.4 \text { Making sense of disease and treatment } & \text { Making sense of disease and treatment } & \mathrm{d} 1 ; \mathrm{d} 570 \\ 10.5 \text { Monitoring treatment and disease } & \text { Monitoring } & \mathrm{nd} \\ & \text { Monitoring treatment and disease } & \mathrm{d} 570 \\ 10.6 \text { Management of own health } & \text { Management of own health } & \mathrm{d} 570\end{array}$

\section{Theme 11: Activities linked to Participation}

\begin{tabular}{|c|c|c|}
\hline Subtheme & Meaningful concept & ICF codification \\
\hline \multirow{3}{*}{$\begin{array}{l}\text { 11.1 Activity limitations lead to restrictions in community } \\
\text { and professional life }\end{array}$} & Activity limitations & nd \\
\hline & Community life & d9 \\
\hline & Professional life & d850 \\
\hline \multirow{2}{*}{$\begin{array}{l}11.2 \text { Enacting treatment activities implies engaging with } \\
\text { health care professionals }\end{array}$} & Treatment regimen & $\mathrm{nc}$ \\
\hline & health care professionals & e355; e450 \\
\hline
\end{tabular}




\section{Theme 12: Activities linked to Body Functions and Structures}

\begin{tabular}{|c|c|c|}
\hline Subtheme & Meaningful concept & ICF codification \\
\hline \multirow[t]{3}{*}{ 12.1 Running triggers voice and respiratory symptoms } & Running & d455 \\
\hline & Voice symptoms & b310 \\
\hline & respiratory symptoms & b460 \\
\hline \multirow[t]{2}{*}{ 12.2 Finding strategies to deal with side-effects } & Copying strategies & pf; d570 \\
\hline & Side-effects & nd \\
\hline \multirow{4}{*}{$\begin{array}{l}12.3 \text { Respiratory symptoms limit the simultaneous } \\
\text { activities of speaking and running }\end{array}$} & Respiratory symptoms & b450; b460 \\
\hline & Simultaneous activities & $\mathrm{nc}$ \\
\hline & speaking & d330 \\
\hline & Running & d455 \\
\hline \multirow{2}{*}{$\begin{array}{l}12.4 \text { Treatment activities prompted by perceptions of } \\
\text { respiratory symptoms }\end{array}$} & Treatment regimen & $\mathrm{nc}$ \\
\hline & Respiratory symptoms & b450; b460 \\
\hline
\end{tabular}

\section{Theme 13: Participation}

Subtheme

Meaningful concept

ICF codification 
13.2 Restriction of physical activities with peers

13.3 Participation as a priority regarding treatment decisions

Theme 14: Participation linked to Body Functions and Structures

\begin{tabular}{|c|c|c|}
\hline Subtheme & Meaningful concept & ICF codification \\
\hline \multirow[t]{2}{*}{$\begin{array}{l}\text { 14.1 Functions related with eating limit recreation and } \\
\text { leisure activities }\end{array}$} & Eating & b5105; d550 \\
\hline & recreation and leisure activities & d920 \\
\hline \multirow[t]{2}{*}{ 14.2 Pain limiting capacity to work } & Pain & b280 \\
\hline & capacity to work & d850 \\
\hline \multirow{2}{*}{$\begin{array}{l}\text { 14.3 Perception of symptoms depends on the extent of } \\
\text { participation restrictions }\end{array}$} & Perception of symptoms & nd \\
\hline & participation restrictions & nd \\
\hline $\begin{array}{l}\text { 14.4 Side effects limiting social participation (playing } \\
\text { cards with friends) }\end{array}$ & Side effects & nd \\
\hline
\end{tabular}


14.5 Speaking dysfunction influencing participation

Speaking dysfunction

Participation

Symptoms

Participation with peers

Symptoms

Volunteering

14.7 Symptoms limiting volunteering

\section{Volunteering}

\section{Theme 15: Body Functions and Structures}

\section{Subtheme}

15.1 Anxiety, frustration, distress and depression

15.3 Chest, pharynx and lungs

15.4 Coughing and sputum production

15.5 Fatigue

\section{Meaningful concept}

\section{ICF codification}

Anxiety, frustration and distress

Depression

b152; d240

hc

Blood

b4; s410

Chest, pharynx and lungs

s330; s430

Coughing

b450

sputum production

nc

Fatigue 


\begin{tabular}{|c|c|c|}
\hline 15.6 Kidneys & Kidneys & b610; s6100 \\
\hline 15.7 Joints and muscles & Joints and muscles & s7; b7 \\
\hline 15.8 Pain & Pain & b280 \\
\hline 15.9 Poor vision & Poor vision & b210; s2 \\
\hline 15.10 Shoulder & Shoulder & s720 \\
\hline 15.11 Shortness of breath and wheezes & Shortness of breath and wheezes & b450; b460 \\
\hline \multirow{3}{*}{$\begin{array}{l}15.12 \text { Stomach and bowel problems (pain, flatulence and } \\
\text { constipation) }\end{array}$} & Stomach pain & s530; b28012 \\
\hline & bowel & s540 \\
\hline & Constipation and flatulence & b525 \\
\hline 15.13 Vice and speaking & Vice and speaking & d330; b310; s3 \\
\hline 15.14 Being overweight & Being overweight & b530 \\
\hline \multirow{2}{*}{$\begin{array}{l}15.15 \text { Absence of symptoms limits adherence to } \\
\text { treatment }\end{array}$} & Symptoms & nd \\
\hline & Adherence & $\mathrm{nc}$ \\
\hline 15.16 Skin & Skin & b8; s8 \\
\hline 15.17 Sleep & Sleep & b134 \\
\hline 15.18 Being irritable & Being irritable & b1263; pf \\
\hline
\end{tabular}


15.19 Sickness

Sickness

b510

15.20 Increased need to urinate frequently

Increased need to urinate frequently

b6201

15.21 High blood pressure

High blood pressure

b420

15.22 Dizziness

Dizziness

b2401

15.23 Allergic reactions

Allergic reactions

b4351 